\title{
Quality Evaluation of 'Sunburst' Cherries Harvested at Different Ripeness Stages
}

\author{
A.C. Agulheiro-Santos, V. Palma, G. Machado, A.E. Rato and M.J. Cabrita \\ Universidade de Évora \\ Instituto de Ciências Agrárias e Ambientais Mediterrânicas (ICAAM) \\ Escola de Ciências e Tecnologia \\ 7000 Évora \\ Portugal
}

Keywords: sweet cherry, 'Sunburst', quality, ripeness stage, total antioxidant activity

\begin{abstract}
The sweet cherry 'Sunburst' is highly appreciated by consumers due to its organoleptic traits. Regional producers tend to harvest cherries sooner in order to increase their profits. With the aim of understanding the consequences of this we have tested the effect of different ripeness stages at the moment of harvesting on fruit quality. Quality parameters tested included external colour $\left(L^{*}, a^{*}, b^{*}\right)$, fruit texture, total soluble solids (TSS), and titratable acidity (TA). To evaluate nutritional quality total antioxidant activity was measured too. Once again, and in agreement with results obtained in previous studies, we conclude that there is no advantage in picking less ripe cherries.
\end{abstract}

\section{INTRODUCTION}

The sweet cherry 'Sunburst' is highly appreciated by consumers due to its organoleptic traits. Regional producers tend to harvest cherries sooner in order to increase their profits. The southeast region of Portugal produces several cultivars that seem to be well adapted to the local environment. These are small acreage orchards, with several cultivars, one of them 'Cereja de S. Julião' has a Protected Designation of Origin (PDO), and is exploited by farmers in a traditional system. However, due to the limited economies of these producers, very few studies have been directed to the sweet cherry crop in that region.

Skin colour is the most important indicator of quality and maturity of fresh cherry and depends on the anthocyanin content (Esti et al., 2002; Usenik et al., 2008). Anthocyanin pigments are responsible for the attractive colours of many fruits and vegetables. Anthocyanins are relatively unstable and often undergo degradative reactions during processing and storage. Measurement of total anthocyanin pigment content along with indices for the degradation of these pigments is very useful in assessing the colour quality of these foods. Interest in the anthocyanin content of foods and nutraceutical preparations has been intensified because of their possible health benefits. Antioxidants seem to play an important role as a health-protecting factor. The antioxidant activity of phenolics is mainly due to their redox properties which make them act as reducing agents, hydrogen donors, and singlet oxygen quenchers (Teixeira et al., 2009).

With the aim of understanding the influence of different ripeness stages at the moment of harvesting on changes in quality and nutritional aspects of cherries due the consequences of this on the potential health protective effects, we studied the parameters external colour ( $\left.\mathrm{L}^{*}, \mathrm{a}^{*}, \mathrm{~b}^{*}\right)$, soluble solids content (TSS), titratable acidity (TA), total polyphenols and anthocyanins content and antioxidant activity.

\section{MATERIAL AND METHODS}

Fruits were picked at the same time, but separated according to different maturity stages (unripe, ripe and overripe stages) based on visual fruit colour. The designation of "ripe" corresponds to fruits harvested at the usual stage of maturity for this cultivar at that region, bright red colour, the "unripe" corresponds to a light red colour and the "overripe" to dark red colour. These colours may be compared with the three first stages ("rojo 
claro", "rojo" and "rojo caoba"), on the cherry maturity indices used by the "Pontifica Universidad Católica de Chile".

The external colour fruit texture, TSS and TA were performed in fresh fruit, while the total polyphenols, total anthocyanins and antioxidant activity were measured from cherry extracts obtained from freeze dried fruits. The external colour $\left(\mathrm{L}^{*}, \mathrm{a}^{*}, \mathrm{~b}^{*}\right.$ coordinates colour space) was measured in equatorial zone using a colorimeter (Minolta CR-300), TSS was measured using a digital refractometer (results were expressed in ${ }^{\circ}$ Brix) and TA using a Crison Compact Titrator (results were expressed as percent malic acid equivalents).

For anthocyanins, sweet cherry extracts were obtained from $1 \mathrm{~g}$ of freeze dried fruits with $10 \mathrm{ml}$ of acidified methanol $(0.2 \% \mathrm{HCl})$. After 16 hours at $-22^{\circ} \mathrm{C}$ the samples were centrifuged at $10000 \mathrm{rpm}$ for $15 \mathrm{~min}$ and filtered.

The total polyphenols content of the extracts was assessed using the FolinCiocalteu phenol reagent method (Singleton and Rossi, 1965) and expressed as Galic Acid Equivalents (GAE) in mg per $100 \mathrm{~g}$ of fresh weight (FW). The total anthocyanins was determined according to the modified method of Ribereau-Gayon and Stonestreet (1965) and expressed as Malvidin Equivalents in mg per $100 \mathrm{~g}$ of FW. The determination of antioxidant activity of the extract was evaluated using DPPH radical scavenging assay (Brand Williams et al., 1995). The percentage inhibition of DPPH was calculated according to the formula:

$$
\% \text { Inhibition }=\left[\frac{A b-A a}{A b}\right] \times 100
$$

where: $A b$ is the absorption of blank sample $(\mathrm{t}=0)$ and $A a$ is the absorption of tested extract at the end of reaction $(\mathrm{t}=30 \mathrm{~min})$. Data were analyzed by ANOVA, for colour coordinates $\mathrm{L}^{*} \mathrm{a}^{*} \mathrm{~b}^{*}$, total polyphenols, anthocyanins content and antioxidant activity considering the variable ripening stage with 3 levels. When necessary mean comparisons were performed using Tukey test for $\mathrm{p}<0.05$. For all the statistical analysis Statistica 6.0 program was used.

\section{RESULTS AND DISCUSSION}

As expected, all colour coordinates $L^{*} a^{*} b^{*}$, were significantly different $(p<0.05)$ among samples obtained in different ripening stages. These results corroborate our visual selection by maturity stage of cherries done in the field and confirmed at the laboratory. All the colour coordinates decreased with ripening process in the orchard. This means that cherries became darker and redder, as expected (Fig. 1). The results of Tukey test for mean comparison revealed that all the three ripening stages are significantly different for all the colour coordinates. Colour measurement with $\mathrm{L}^{*} \mathrm{a}^{*} \mathrm{~b}^{*}$ coordinates should be used as a main criterion for assessing maturity and also harvest time. The use of a color chart that relates to the $\mathrm{L}^{*} \mathrm{a}^{*} \mathrm{~b}^{*}$ values obtained should be developed and proposed to farmers.

Both soluble solids content (TSS) and titratable acidity (TA) had a similar behaviour, increasing with the ripening stage. These values highlight the fact that fruits harvested in an unripe stage have the worst organoleptic features, since these are two parameters that consumers consider determinant for their quality evaluation. Values higher than $17^{\circ}$ Brix are referred by Edin et al. (1997) as very high for different sweet cherry cultivars, so the ripe $\left(16.6^{\circ} \mathrm{Brix}\right)$ and over ripe $\left(21.4^{\circ} \mathrm{Brix}\right)$ sweet cherries studied belong to that quality classification. On the other hand unripe cherries with $12.2^{\circ}$ Brix can be classified as medium sweetness by the same author. The results of titratable acidity (\% malic acid) were 0.463 for unripe cherries, 0.556 for ripe cherries and 0.666 for overripe cherries.

The content of total polyphenols and total anthocyanins increased significantly with the ripeness stage (total polyphenols for unripe, ripe and over ripe fruits 129.1, 154.7 , and $253.4 \mathrm{mg} / 100 \mathrm{~g} \mathrm{FW}$, respectively; and total anthocyanins were 20.09, 63.03, and $216,19 \mathrm{mg} / 100 \mathrm{~g} \mathrm{FW}$, respectively). ANOVA results show $\mathrm{p}<0.05$ for both and 
$\mathrm{F}=135.850$ for total polyphenols and $\mathrm{F}=410.206$ for total anthocyanins. Tukey test revealed significant mean differences among the three different ripeness stages for both parameters. Notice the dramatic increase of total anthocyanins observed from ripe fruits to overripe fruits (Figs. 2 and 3). Gonçalves (2006) found identical behavior for phenolics indicating that they are always higher in ripe than in partially ripe cherries.

The antioxidant activity remained stable at the first two stages of maturity, presenting a significant increase from the ripe to the overripe fruits $(63.14,54.87$, and $80.41 \mathrm{mg} / 100 \mathrm{~g} \mathrm{FW}$ for unripe, ripe and overripe fruits, respectively). For antioxidant activity ANOVA results are also significantly different $(\mathrm{F}=8.486$ and $\mathrm{p}=0.0178)$ but Tukey test confirmed that cherries from ripe stage are significantly different from overripe cherries (Fig. 4). Serrano et al. (2004) studied different quality parameters during fruit development and ripening and found that antioxidant activity and phenolic content reached the highest values for the most mature cherries. This is important information to consider deciding the ripeness stage at harvest for cherries, due to its significance in nutritional value of cherries.

\section{CONCLUSIONS}

The results obtained in this study, and also in anterior research on sweet cherry, and the fact that this is a non-climacteric fruit, provide a basis to conclude that there is no economical advantage for producers, neither quality improvement for consumers in picking less ripe cherries. Riper cherries should be better from organoleptic and nutritional points of view, with a strong advantage in higher total polyphenols and total anthocyanins, and a less notable difference in antioxidant activity.

\section{ACKNOWLEDGEMENTS}

To RITECA/INTERREG for support of this research work.

\section{Literature Cited}

Agulheiro Santos, A.C., Palma, V., Rato, A.E., Machado, G., Lozano, M. and González, D. 2009. Quality evaluation of cherry 'Sweetheart' under different storage conditions. VI International Cherry Symposium. Viña del Mar, Chile.

Brand-Williams, W., Cuvelier, M.E. and Berset, C. 1995. Use of free radical method to evaluate antioxidant activity. Lebensm. Wiss. Thechnol./Food Sci. 28:25-30.

Edin, M., Lichou, J. and Saunier, R. 1997. Cerise, les Varieties et leur Conduite. Ctifl, 238.

Esti, M., Cinquanta, L., Sinesio, F., Moneta, E. and Di Matteo, M. 2002. Physicochemical and sensory fruit characteristic of two sweet cherry cultivars after cool storage. Food Chem. 76:399-405.

Giusti, M.M. and Wrolstad, R.E. (eds.). 2001. Characterization and measurement of anthocyanins by UV-Visible spectroscopy. Current Protocols in Food Analytical Chemistry F1.2.1-F1.2.13.

Gonçalves, B.M.C. 2006. Ecofisiologia da cerejeira (Prunus avium L.), composição fenólica e actividade antioxidante dos frutos. Ph.D. thesis. UTAD. Vila Real, Portugal.

Ribereau-Gayon, P. and Stonestreet, E. 1965. Le dosage des anthocyanes dans les vins rouges. Bull. Soc. Chim. 9:2649-2652.

Sampaio, A., Agulheiro-Santos, A.C. and Oliveira, C.M. 2006. Efeito de diferentes estados de maturação à colheita na capacidade de conservação de cereja 'Sunburst'. VIII Simposio Nacional y Ibérico de Maduración y Post-Recolección. Orihuela 27-30 Septiembre 2006.

Serrano, M., Martínez-Romero, D., Castillo, S. and Valero, D. 2004. Cambios en las propiedades organolépticas y funcionales durante la maduración de la cereza. Actas do IV Simpósio Ibérico, I Nacional, VII Espanhol de Maturação e Pós-Colheita 2004, p.39-43.

Singleton, V.L. and Rossi, J.A. 1965. Colourometry of total phenolics with phosphomolybdic-phospholungistic acid reagents. Am. J. Enol. Vitic. 16:144-158. 
Teixeira, D.M., Canelas, V.C., Martins do Canto, A., Teixeira, J.M.G. and Barrocas Dias, C. 2009. HPLC-DAD Quantification of phenolic compounds contributing to the antioxidant activity of Maclura pomifera, Ficus carica and Ficus elastica extracts. Anal. Letters 42:2986-3003.

Usenik, V., Stampar, F. and Fajt, N. 2008. Sweet cherry rootstock testing in Slovenia. Acta Hort. 795:273-276.

\section{Figures}

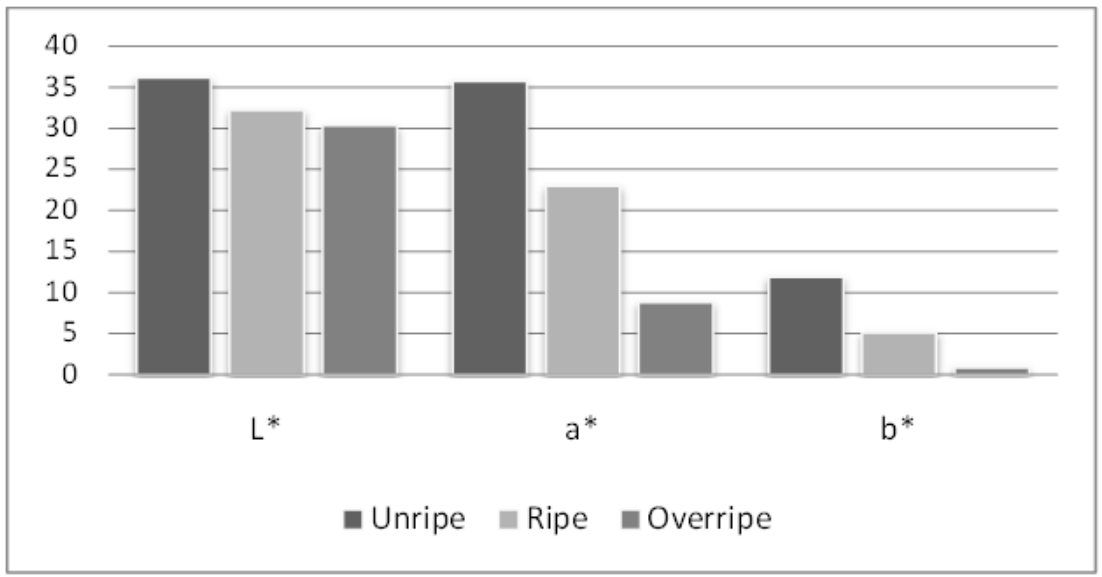

\begin{tabular}{|l|c|c|c|}
\hline & $\mathrm{L}^{*}$ & $\mathrm{a}^{*}$ & $\mathrm{~b}^{*}$ \\
\hline Unripe & $36.14 \pm 3.514$ & $35.75 \pm 5.645$ & $11.92 \pm 3.981$ \\
\hline Ripe & $32.24 \pm 1.154$ & $22.98 \pm 4,127$ & $5.18 \pm 1.427$ \\
\hline Overripe & $30.34 \pm 1.113$ & $8.85 \pm 2,854$ & $0.87 \pm 0.601$ \\
\hline
\end{tabular}

Fig. 1. 'Sunburst' sweet cherry color coordinates $L^{*} a^{*} b^{*}$ at different ripeness stages. Data are means + standard deviation.

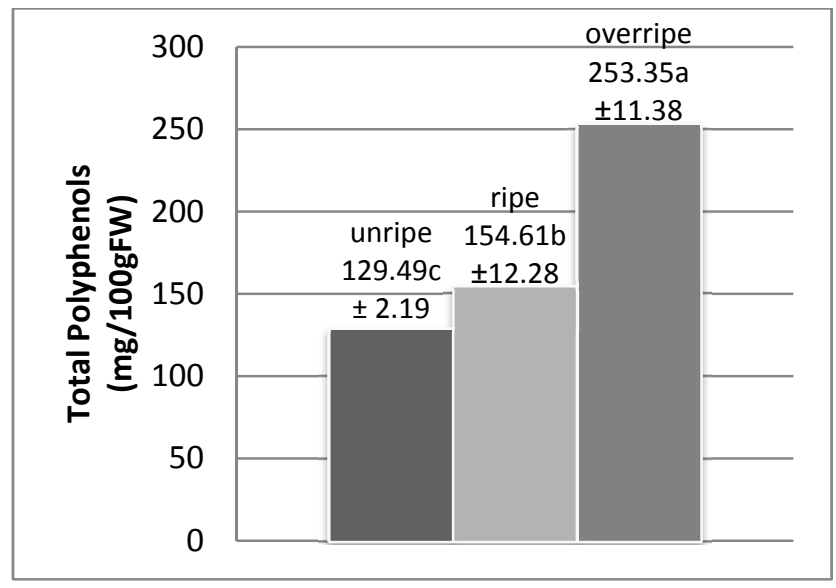

Fig. 2. Total polyphenols concentrations of 'Sunburst' sweet cherry harvested at different ripeness stages. Data are means + standard deviation. 


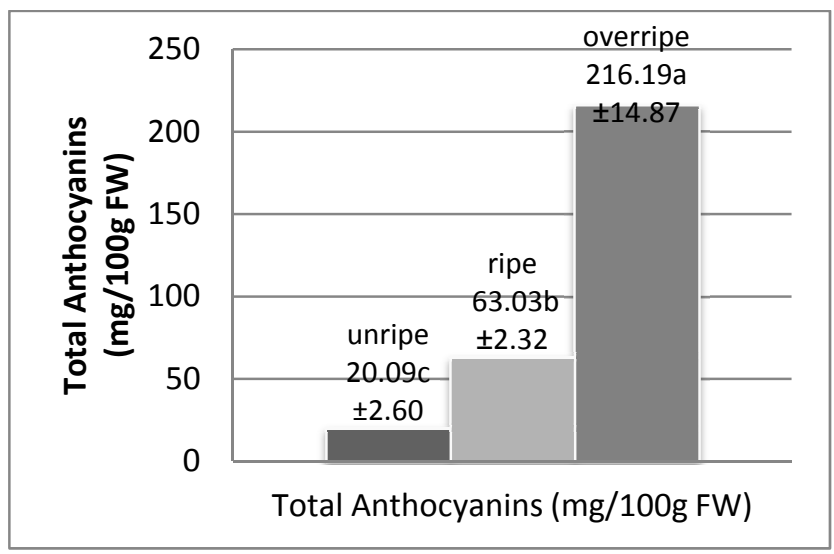

Fig. 3. Total anthocyanin concentrations of 'Sunburst' sweet cherry harvested at different ripeness stages. Data are means + standard deviation.

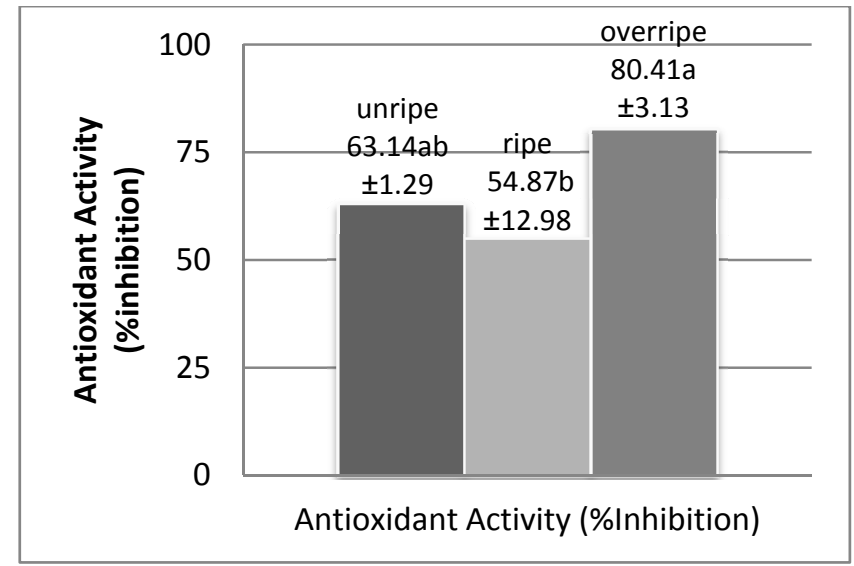

Fig. 4. Antioxidant activity of 'Sunburst' sweet cherry harvested at different ripeness stages. Data are means + standard deviation. 
